\title{
Anti-Quorum Sensing Potential of Antioxidant Quercetin and Resveratrol
}

\author{
Demet Erdönmez ${ }^{1}$, Abbas Yousefi $\operatorname{Rad}^{2}$, Nilüfer Aksöz 3 \\ ${ }^{1}$ Institute of Science, Department of Biology, Hacettepe University, Ankara, Turkey; ${ }^{2}$ Yüksek Ihtisas University, \\ Medical Faculty, Department of Medical Microbiology, Ankara,Turkey; ${ }^{3}$ Faculty of Science, Department of \\ Biology, Hacettepe University, Ankara, Turkey.
}

\begin{abstract}
Quorum sensing system plays an active role in the regulation of pathogenicity of many microorganisms. Inhibition of pathogenicity or virulence factors will increase the success of treatment by preventing the development of antibiotic resistance. In this study, anti-quorum sensing activities of quercetin and resveratrol compounds, which have antioxidant property without damaging to host, have been determined via using biosensor bacteria: Chromobacterium violaceum ATCC 12472 and Chromobacterium violaceum CV026. As quorum sensing inhibitors, quercetin and resveratrol's cutting off the bacterial communication will prevent the treatment failures caused by the development of bacterial resistance. The development of layered drugs with antioxidant compounds such as quercetin and resveratrol will pave the way for new horizons for new therapeutic strategies.
\end{abstract}

Key words: Anti-quorum sensing, Resveratrol, Quercetin, Antioxidant

\footnotetext{
Author for correspondence: demet.erdonmez@gmail.com
} 


\section{INTRODUCTION}

Many civilizations have used plants for treatment purposes throughout the history of civilizations. The methods of herbal treatment written on the papyrus in the mummies tomb of ancient Egyptian civilizations have been replaced by tablets in Hittite period and have come up to today as written sources ${ }^{1}$. The implementations of herbal treatment have also been come across in the tablets of Roman Empire dominating Europe and Asia Minor. Herbal therapy has not only been used in

ancient times but also come up to today and it still continues to be used ${ }^{1}$. Benefiting from plant extracts particularly for the treatment of pathogens, has also contributed to the development of pharmaceutical sciences. Besides being commonly found in

nature, plants can also be used as food sources by living bodies 18 . The toxic effects of the plants that are used have enabled them to be preferable for many antimicrobial researches.

As a result of using antimicrobial efficacy molecule for the elimination of pathogens, microorganisms have developed resistance to antimicrobial agents via developing

different mechanisms ${ }^{1,2}$. Therefore, narrowing the areas of many antibiotics used

for treatment has led to the development of new antimicrobial agents 2,7 . Plant extracts have pioneered among the new resources. No matter how efficient the plant extracts have been identified for treatment, it has also been observed to damage to living bodies when they are not used appropriately ${ }^{7}$. In many studies conducted, the compounds with the lowest damage to living bodies have been preferred and the compounds with antioxidant properties, which are popular topics of our age, have been focused on. Some molecules with antioxidant properties are known to be used as antimicrobial agents $1,3,1$. Decreasing effectiveness of antimicrobial agents on the virulence of the bacteria, has led to researches to be conducted on bacterial communication system (quorum sensing) which is responsible for the organization of this mechanism 2,1 . Besides elucidating the quorum sensing, the prevention of this system will ensure success against the bacterial virulence 11 .

Various plant extracts are used in the inhibition of bacterial communication system which is also referred as anti-quorum sensing ${ }^{3}$. The content of these extracts consists of a variety of compounds. How these compounds are effective on living bodies have not been elucidated in researches. In our study, quercetin and resveratrol compounds, whose antioxidant properties are known, have been used. Quercetin is the yellow pigment which is commonly found in the pericarp within the flavonoid group such as apple, onion, tea, and red grape ${ }^{12}$. Anti-carcinogenic, antiinflammatory, and anti-histamine effects of quercetin have been identified in several studies ${ }^{4}$. Resveratrol is a natural phytoalexin found in particularly red grapes, pineapple, and peanuts ${ }^{1}$. In addition to protecting plants from UV rays, it also benefits in protection against some pathogens. For example, resveratrol, under adverse weather conditions, is produced by black grape against fungal factors. When compared to many other substances, resveratrol is a molecule with high antioxidant properties. Besides anti-aging effects, its effect of lowering blood fat has been

determined 4 .

\section{MATERIAL AND METHODS}

\section{Determining Anti-Quorum Sensing Activity of Quercetin and Resveratrol Molecule}

Quercetin (Sigma Aldrich), which has the properties of a natural antioxidant compound and different concentrations of resveratrol (Sigma Aldrich) have been used to observe anti-quorum sensing activity in this study. Quercetin is dissolved in 
Antioxidants as antiquorum sensing agents

dimethyl sulfoxide (DMSO) and resveratrol in ethanol. As C6-AHL (N -HexanoylL-homoserine lactone) molecule is frequently used by Gram negative bacteria as communication molecule, anti-quorum sensing activity experiments have been conducted on this molecule. Obtained from the University of Nottingham, pure N Hexanoyl-L- homoserine lactone molecule has been prepared as $2 \mathrm{mg} / \mathrm{ml}$ (ethyl acetate) to be used.

\section{Anti-Quorum Sensing Disc diffusion and Agar Diffusion Test}

After C. violaceum biosensor strain culture turbidity produced at $30^{\circ} \mathrm{C}$ for 18 hours is adjusted to Mc Farland $0.5\left(10^{8} \mathrm{cfu} / \mathrm{ml}\right), 100 \mathrm{ul} C$. violaceum 026 and $50 \mathrm{ul} \mathrm{C6-HSL}$ extracts have been added to $10 \mathrm{ml}$ soft Luria Bertani agar medium. Quercetin at different concentrations $(2,5,10,50,100,150,200,250 \mathrm{mg} / \mathrm{ml})$ or resveratrol impregnated discs have been placed on solidifying soft LB-agar medium and has been left in the incubator at $30^{\circ} \mathrm{C}$ for 48 hours for incubation. For the agar diffusion test; when LB medium consisting of $0.9 \%$ agar, $100 \mu \mathrm{l} C$. violaceum 026 and $50 \mu \mathrm{l}$ C6-HSL extract has solidified, $4 \mathrm{~mm}$ wide wells have opened. Quercetin and resveratrol at different concentrations $(2,5,10,50,100,150,200,250 \mathrm{mg} / \mathrm{ml})$ have been added to these opened wells. Petri dishes have been left for incubation at $30^{\circ} \mathrm{C}$ for 48 hours. Agar diffusion and disc diffusion tests have been repeated three times

$12,10,3,4,1,11$.

\section{Spectrophotometric Measurement of Anti-Quorum Sensing Activity of Quercetin and Resveratrol}

In accordance with the amounts given in Table 1., Quercetin and resveratrol at different concentrations $(2,5,10,50,100,150,200,250 \mathrm{mg} / \mathrm{ml})$ have been added to eppendorf tubes. The amount of violacein pigment formed after incubation has been measured at $585 \mathrm{~nm}$ in spectrophotometer and anti-quorum sensing activity has been detected.

\section{Violacein Pigment Isolation}

Extraction of violacein pigment from liquid culture has been done as Blosser and Gray ${ }^{1} .100 \mathrm{ul}$ from $20 \mathrm{ml}$ of 15 -hour fresh culture of $C$. violaceum 026 strain produced in LB medium has been taken and cultivated in $1 \mathrm{~m} 1 \mathrm{LB}$ medium in the framework of procedure given in Table 1 . The culture left for incubation at $30^{\circ} \mathrm{C}$ for 24 hours has been mixed with vortex and $200 \mathrm{ul}$ culture has been taken from this tube and transferred to eppendorf tube. $200 \mathrm{ul}$ of $10 \%$ sodium dodecyl sulfate (SDS) has been added on it for the lysis of the cells and vortexed for 5 seconds and kept for 5 minutes at room temperature. $900 \mathrm{ul}$ butanol (as $50 \mathrm{ml} \mathrm{n}$-butanol $+10 \mathrm{ml}$ distilled water) which is saturated with water for the violacein pigment isolation, has been added to tube and vortexed for 5 seconds. Thereafter, it has been centrifuged for 5 minutes at 10,000 rpm. The upper phase has been transferred into a new tube and read at $585 \mathrm{~nm}$ on microplate spectrophotometer and the amount of violacein has

been determined 3 . 
Table 1. Quercetin and resveratrol Application Procedure

\begin{tabular}{lcccl}
\hline & A & B & C & Final concentration \\
\hline Luria Bertani Broth & $895 \mu \mathrm{l}$ & $890 \mu \mathrm{l}$ & $890 \mu \mathrm{l}$ & \\
CV026 & $100 \mu \mathrm{l}$ & $100 \mu \mathrm{l}$ & $100 \mu \mathrm{l}$ & $1 \times 10^{8} \mathrm{cfu} / \mathrm{ml}$ \\
C6-AHL & $50 \mu \mathrm{l}$ & $50 \mu \mathrm{l}$ & $50 \mu \mathrm{l}$ & $150 \mu \mathrm{mol} / \mathrm{ml}$ \\
Quercetin & - & - & $5 \mu \mathrm{l}$ & Different concentration $\quad$ of \\
Resveratrol & - & - & $5 \mu \mathrm{l}$ & Resveratrol or quercetin \\
& & & & $(2,5,10,50,100,150,200,250 \mathrm{mg} / \mathrm{ml})$ \\
DMSO or Etanol & - & $5 \mu \mathrm{l}$ & - & \\
Total volume & $1045 \mu \mathrm{l}$ & $1045 \mu \mathrm{l}$ & $1045 \mu \mathrm{l}$ & \\
\hline
\end{tabular}

\section{RESULTS AND DISCUSSION}

\section{Anti-Quorum Sensing Activity of Quercetin Molecule}

As mentioned, 2, 5, 10, 50,100, 150, 200, $250 \mathrm{mg} / \mathrm{ml}$ concentrations of Quercetin have been prepared by dissolving in DMSO. As a result of the study, it has been determined that Quercetin with antioxidant properties has had positive impact on living bodies and C6-HSL which is the bacterial communication molecule. As a result of both agar diffusion test and disc diffusion test, different concentrations of quercetin have been observed to inhibit violacein pigment production (Figure 1 and Figure 2).

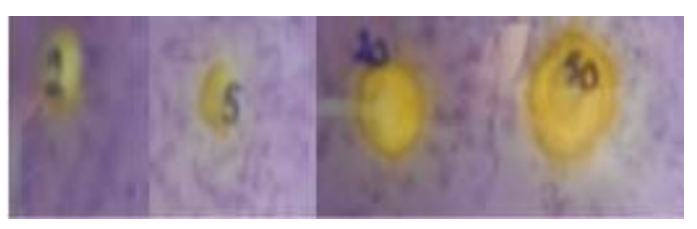

Figure 1. Anti-Quorum Sensing Activity of Quercetin $(50 \mathrm{mg} / \mathrm{ml})$

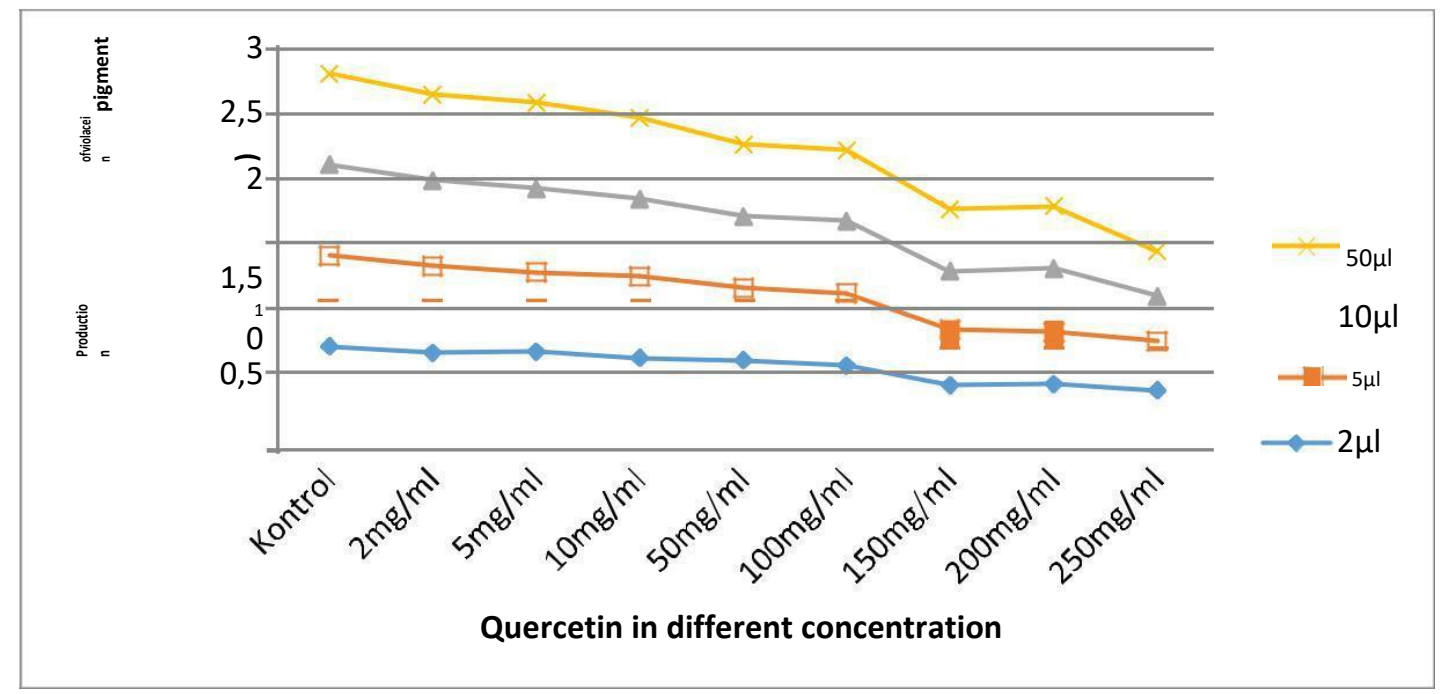

Figure 2. The effect of different concentrations of resveratrol on violacein pigment synthesis.

As it has been observed that the production of bacteria has been inhibited in the zones formed as a result of both agar diffusion and disc diffusion tests (Figure 3), the amount of violacein pigment has been determined by spectrophotometric means 
Antioxidants as antiquorum sensing agents

as a result of formed anti-quorum sensing effect lessening the production of bacteria, and inhibitory effect of quercetin on C6-AHL in addition to studies above.

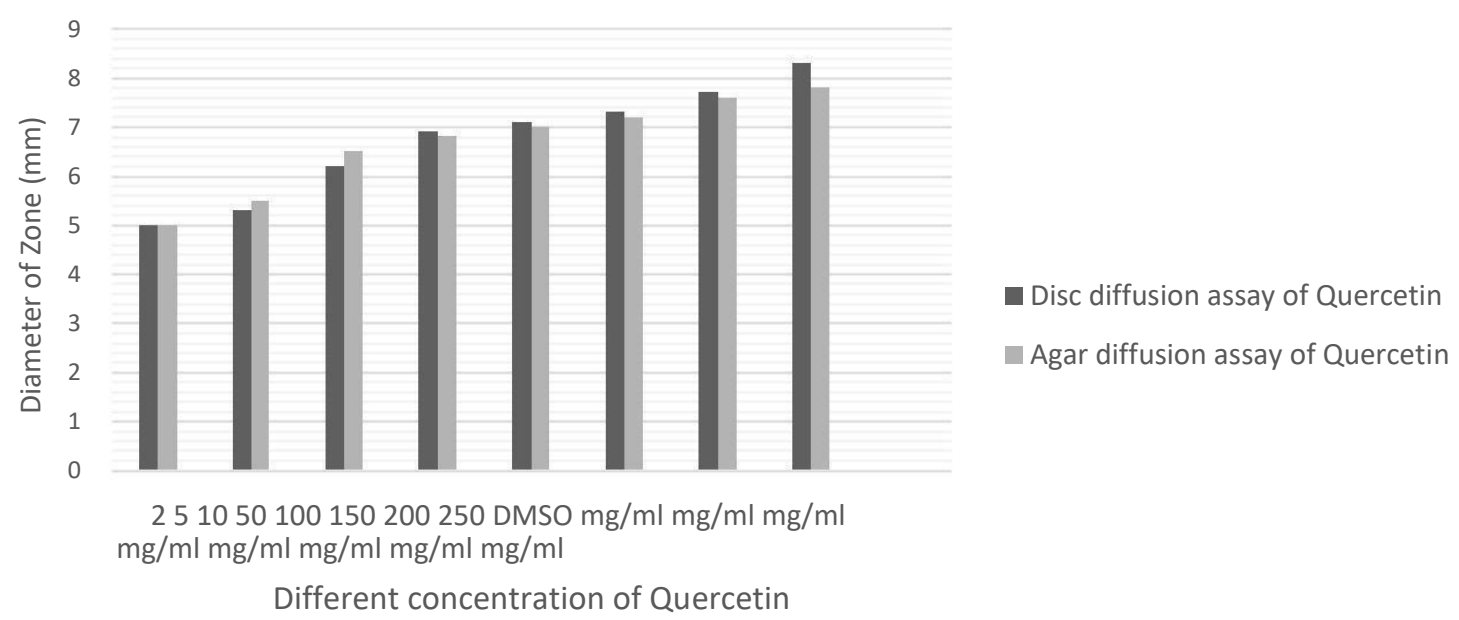

Figure 3. Disc and agar diffusion assay of Quercetin

In this study, the declining production of violacein pigment, in other words quercetin's inhibition of C6-AHL molecule has been determined. C. violaceum 026 biosensor strain produces violacein pigment in the presence of C6-AHL, which is a communication molecule, and this production regulates bacterial communication mechanism called quorum sensing. As known, C6-AHL is used as communication molecule by many Gram negative pathogens bacteria (Pseudomonas aeruginosa, such as E. coli). As shown in Figure 4 the more quercetin concentration increases the more violacein pigment production decreases, in other words quercetin inhibits bacterial communication system.

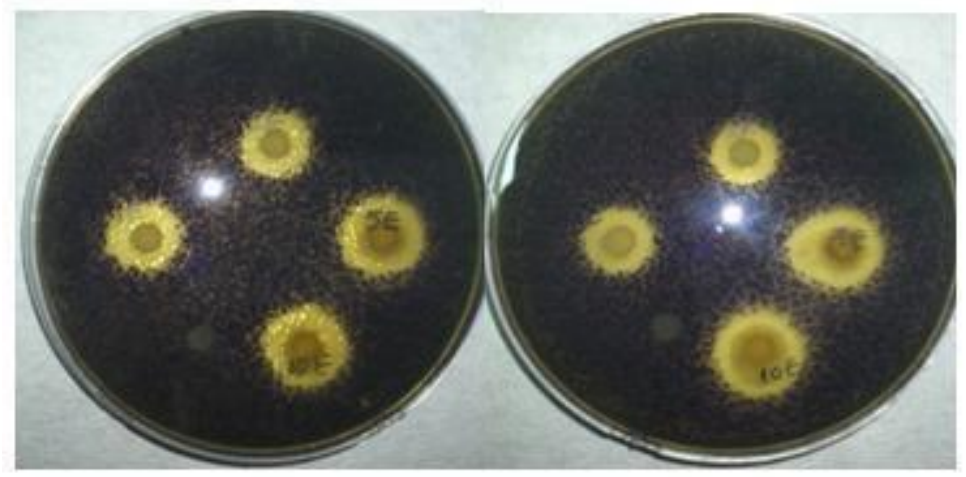

Figure 4. Anti-Quorum Sensing Activity of Resveratrol (50mg/ml)

Thus, that the antioxidant properties of a molecule such as quercetin inhibit bacterial communication paves the way for a new dimension and hope in antibacterial studies. Pathogenic bacteria's gaining resistance against antibacterial agents leads to misapplication of treatment, thereby the extension of the treatment process, and huge economic losses. Also, antibacterial agents in living bodies have huge side effects. Thanks to studies conducted for the cessation of bacterial communication, bacteria will not be able to develop resistance to molecules used and therefore the possibilities of treatment will increase for the patients. This research shows that antiquorum sensing activity of quercetin molecule with antioxidant properties is in 
question and bacterial communication molecules which are frequently used by Gram-negative pathogenic bacteria are inhibited in this way.

\section{Anti-Quorum Sensing Activity of Resveratrol Molecule}

As mentioned, 2, 5, 10, 50,100,150,200, $250 \mathrm{mg} / \mathrm{ml}$ concentrations of resveratrol have been prepared by dissolving in dimethyl sulfoxide (DMSO). For Anti-quorum sensing activity studies, disc diffusion and agar diffusion tests have been conducted and diameters of zones have been measured as mm (Figure 5).

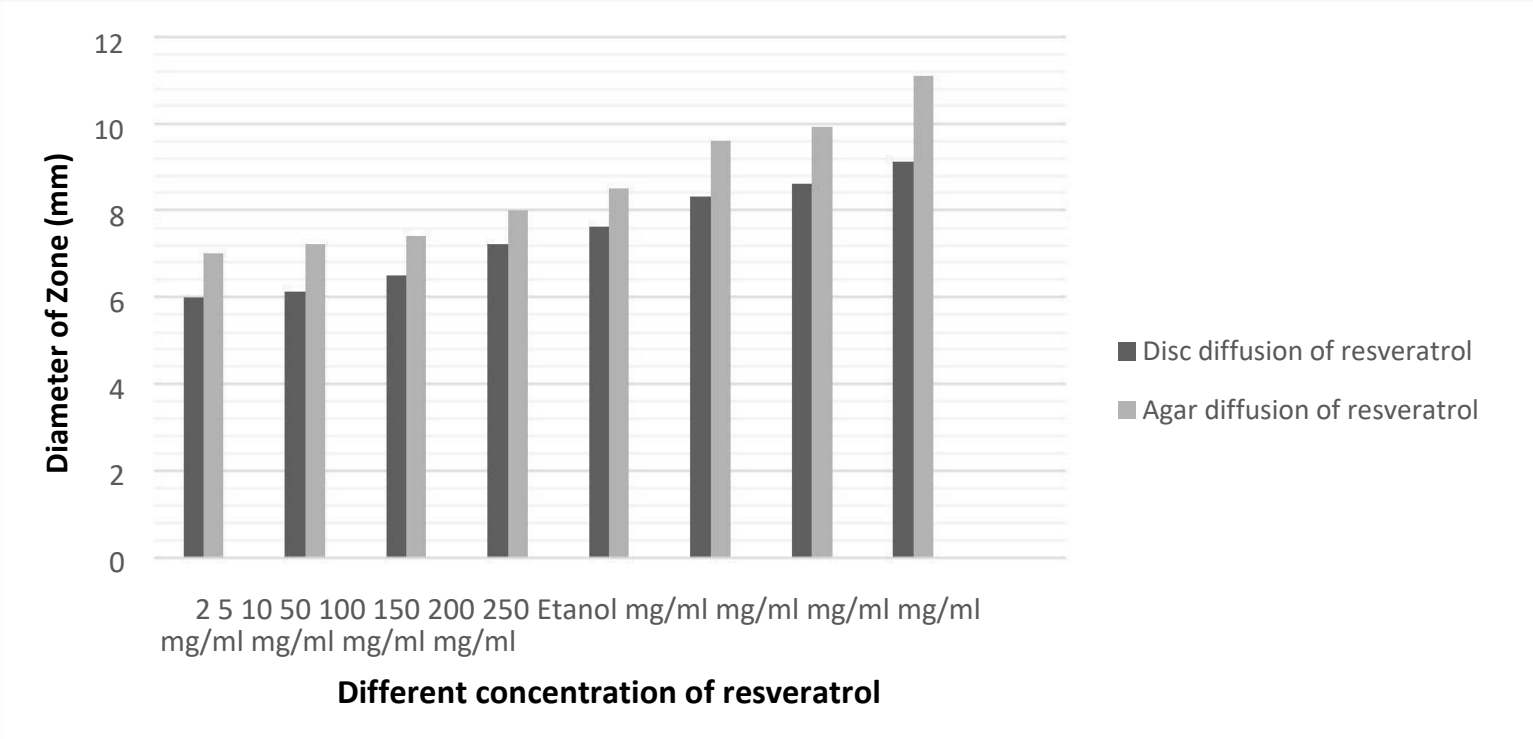

Figure 5: Disc and agar diffusion assay of Resveratrol

Resveratrol is in the forefront among the antioxidant molecules which have positive impact on health. Due to its strong antioxidant properties, it protects the cells from the damage of free radicals. Resveratrol may decrease the effects of certain fungi and bacteria. Based on this property, the efficacy of resveratrol on bacterial communication system has also been analyzed. Anti-quorum sensing activity of resveratrol has been identified on C6-AHL molecule which is commonly used by Gram-negative bacteria species for communication. It has been observed that the more concentration of resveratrol used in different concentration has increased, the more its efficacy on signal molecule has increased. In majority of anti-quorum sensing activity studies, violacein pigment isolation has been conducted besides agar diffusion and disc diffusion tests on Figure 6.

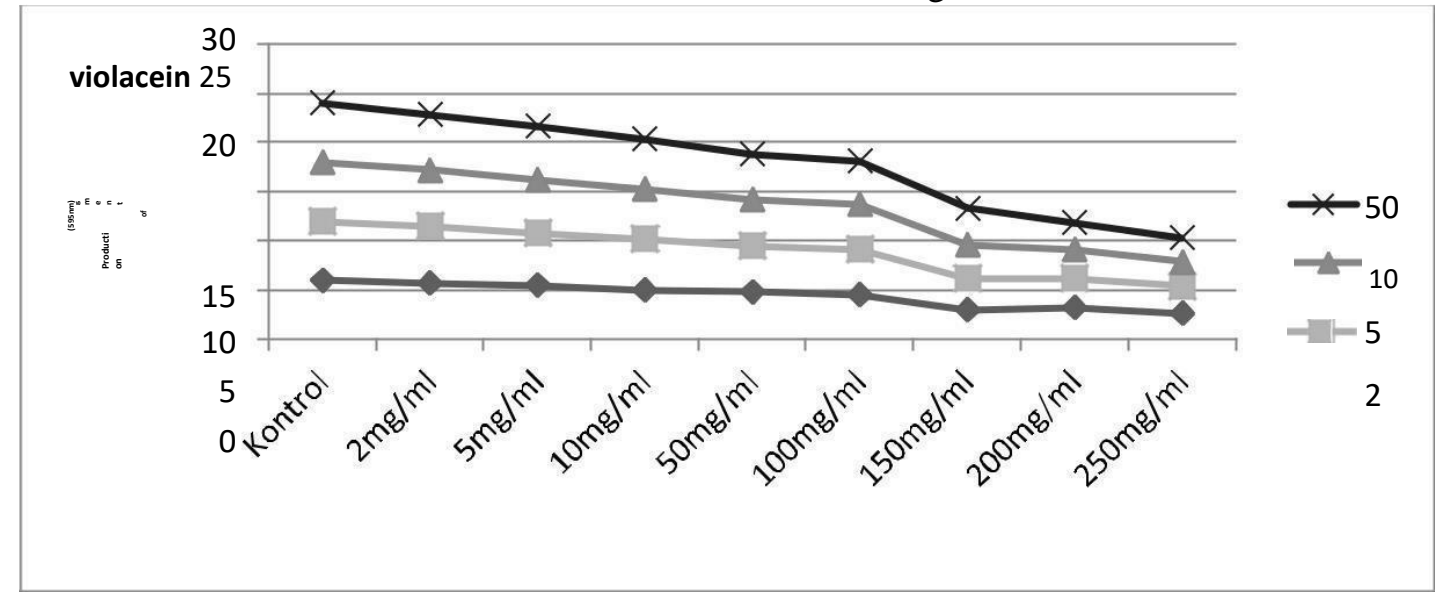

Resveratrol in different concentration

Figure 6. The effect of different concentrations of resveratrol on violacein pigment synthesis. 
Antioxidants as antiquorum sensing agents

The purpose of this is to understand whether the formed effect is antibacterial or it is because of the inhibition of signal molecule. As a result of our study, it has been determined that resveratrol, which is an antioxidant compound, is also effective on bacterial communication system. Anti-quorum sensing activity study is an applicable strategy against the resistance that bacteria developed against antibacterial agents . Kerekes et al., have studied the effects of essential oils extracted from sage, juniper, lemon, and marjoram on biofilm produced by bacteria and yeast and C6-AHL which is a bacterial communication system molecule ${ }^{4}$. As a result of the study, these essential oils have been found as good candidates to inhibit AHL-mediated QS mechanism. Essential oils are known to possess antimicrobial effects . It could be argued that this effect occurs by the way of inhibiting signaling molecules. Adonizio et al, have studied anti-quorum sensing activities of 50 plants with high medical importance isolated in South Florida and determined that 6 plant species have high anti-quorum sensing activity ${ }^{3}$. Alvarez et al.,have determined the efficacy of tea tree and propolis on violacein pigment and proposed that these compounds have antiquorum sensing activity ${ }^{3}$. Similar to this study, Priya et al., have tried the methanolic extracts taken from Phyllanthus amarus Schumac \& Thonn plant known as Chinese herb on Escherichia coli (E. coli) [pSB401], E. coli [pSB1075] and C. violaceum $\mathrm{CVO} 26$ sensor bacteria and determined that the signaling molecules in the medium have been inhibited 11 . Another study about showing the effects of plant extracts and all on quorum sensing mechanism has been conducted by Chu et al and they have proved that Rhubarb, Fructus Gardeniae, and Andrographis paniculata plants have showed anti-quorum sensing activity via using the C.violaceum CV12472 and Pseudomonas aeruginosa PA01 .

\section{CONCLUSIONS}

As it is seen in many of the mentioned studies above, in several plants interwoven with pathogens, some molecules are produced and the effects of bacteria are reduced. These features developed by plants are not just limited to antibacterial effect but also they cut off the communication between bacteria and inhibit their virulence properties. When the conducted studies are analyzed, it is seen that there various compounds in the plant extracts used by the researchers, therefore, which molecule is responsible for anti-quorum sensing activity cannot be explained. In our study, it has been determined that quercetin and resveratrol compounds acquired as pure are efficient in bacterial communication. It has also been determined that quercetin and resveratrol, which gets the attention with their antioxidant properties, can be used in bacterial communication system inhibition, therefore they are the molecules which can replace antibacterial agents without damaging the host.

\section{ACKNOWLEDGEMENTS}

The data of this study have been excerpted from the $\mathrm{PhD}$ thesis of the author. The authors thank Prof. Dr. Robert McLean for collecting biosensor strains (C. violaceum CV026, C. violaceum 31532 and C. violaceum 12472). This work was financed by Hacettepe University Scientific Research Project grant BAP 013BIYY604002. 


\section{REFERENCES}

1- Johnson S. Comparisons Of Therapeutic Foods In Ancient Egypt, Imperial Rome, And Modern Times. History Of Medicine Days. 2005;50.

2- Cockburn A, Barraco RA, Peck WH, Reyman TA. A classic mummy: PUM II. Mummies, Disease and Ancient Cultures. 1998:69-90.

3- Aufderheide AC. The scientific study of mummies: Cambridge University Press; 2003.

4- Buckley SA, Evershed RP. Organic chemistry of embalming agents in Pharaonic and Graeco-Roman mummies. Nature. 2001;413(6858):837-841.

5- Parkins MD. Pharmacological practices of ancient Egypt. HISTORY OF MEDICINE DAYS. 2001;5.

6- David R. Ancient Egyptian Medicine: The Contribution of Twenty-first Century Science. Bulletin of the John Rylands Library. 2013;89(1):157-180.

7- McGovern PE, Mirzoian A, Hall GR. Ancient Egyptian herbal wines. Proceedings of the National Academy of Sciences. 2009;106(18):7361-7366.

8- Spellberg B, Guidos R, Gilbert D, Bradley J, Boucher HW, Scheld WM, Bartlett JG, Edwards J, America IDSo. The epidemic of antibiotic-resistant infections: a call to action for the medical community from the Infectious Diseases Society of America. Clinical Infectious Diseases. 2008;46(2):155-164.

9- Livermore DM. Minimising antibiotic resistance. The Lancet infectious diseases. 2005;5(7):450-459.

10- Singh R, Chidambara Murthy K, Jayaprakasha G. Studies on the antioxidant activity of pomegranate (Punica granatum) peel and seed extracts using in vitro models. Journal of agricultural and food chemistry. 2002;50(1):81-86.

11- Hussain AI, Anwar F, Sherazi STH, Przybylski R. Chemical composition, antioxidant and antimicrobial activities of basil (Ocimum basilicum) essential oils depends on seasonal variations. Food Chemistry. 2008;108(3):986-995.

12- Almajano MP, Carbo R, Jiménez JAL, Gordon MH. Antioxidant and antimicrobial activities of tea infusions. Food chemistry. 2008;108(1):55-63.

13- Otto M. Quorum-sensing control in Staphylococci-a target for antimicrobial drug therapy? FEMS Microbiology Letters. 2004;241(2):135-141.

14- Miller MB, Bassler BL. Quorum sensing in bacteria. Annual Reviews in Microbiology. 2001;55(1):165-199.

15- Waters CM, Bassler BL. Quorum sensing: cell-to-cell communication in bacteria. Annu. Rev. Cell Dev. Biol. 2005;21:319-346.

16-Rutherford ST, Bassler BL. Bacterial quorum sensing: its role in virulence and possibilities for its control. Cold Spring Harbor Perspectives in Medicine. 2012;2(11):a012427.

17- Adonizio AL, Downum K, Bennett BC, Mathee K. Anti-quorum sensing activity of medicinal plants in southern Florida. Journal of Ethnopharmacology. 2006;105(3):427435.

18- Formica J, Regelson W. Review of the biology of quercetin and related bioflavonoids. Food and chemical toxicology. 1995;33(12):1061-1080.

19- Masibo M, He Q. Major mango polyphenols and their potential significance to human health. Comprehensive Reviews in Food Science and Food Safety. 2008;7(4):309-319.

20- Giovinazzo G, D’Amico L, Paradiso A, Bollini R, Sparvoli F, DeGara L. Antioxidant metabolite profiles in tomato fruit constitutively expressing the grapevine stilbene synthase gene. Plant biotechnology journal. 2005;3(1):57-69.

21- Kalinowska M, Bielawska A, Lewandowska-Siwkiewicz H, Priebe W, Lewandowski W. Apples: Content of phenolic compounds vs. variety, part of apple and cultivation model, extraction of phenolic compounds, biological properties. Plant Physiology and Biochemistry. 2014;84:169-188.

22- Filip V, Plockova M, Šmidrkal J, Špičková Z, Melzoch K, Schmidt Š. Resveratrol and its antioxidant and antimicrobial effectiveness. Food Chemistry. 2003;83(4):585-593.

23- Zahin M, Hasan S, Aqil F, Khan MS, Husain FM, Ahmad I. Screening of certain medicinal plants from India for their anti-quorum sensing activity. Indian journal of experimental biology. 2010;48(12):1219-1224. 
Antioxidants as antiquorum sensing agents

24- Chong YM, Yin WF, Ho CY, Mustafa MR, Hadi AH, Awang K, Narrima P, Koh C-LL, Appleton DR, Chan K-GG. Malabaricone C from Myristica cinnamomea exhibits antiquorum sensing activity. Journal of natural products. 2011;74(10):2261-2264.

25- Siddiqui MF, Sakinah M, Singh L, Zularisam AW. Targeting N-acyl-homoserinelactones to mitigate membrane biofouling based on quorum sensing using a biofouling reducer. Journal of biotechnology. 2012;161(3):190-197.

26- Norizan SN, Yin W-FF, Chan K-GG. Caffeine as a potential quorum sensing inhibitor. Sensors (Basel, Switzerland). 2013;13(4):5117-5129.

27- Zaki AA, Shaaban MI, Hashish NE, Amer MA, Lahloub M-FF. Assessment of antiquorum sensing activity for some ornamental and medicinal plants native to egypt. Scientia pharmaceutica. 2013;81(1):251-258.

28- Priya K, Yin W-FF, Chan K-GG. Anti-quorum sensing activity of the traditional Chinese herb, Phyllanthus amarus. Sensors (Basel, Switzerland). 2013;13(11):14558-14569.

29- Blosser RS, Gray KM. Extraction of violacein from Chromobacterium violaceum provides a new quantitative bioassay for $\mathrm{N}$-acyl homoserine lactone autoinducers. Journal of microbiological methods. 2000;40(1):47-55.

30- Inhibition of quorum sensing regulated bacterial functions by plant essential oils with special reference to clove oil. Letters in applied microbiology. 2009;49(3):354-360.

31- Erdönmez D. Nozokomiyal ve Toprak Izolatı Acinetobacter Türlerinin Quorum Sensing Sinyal Moleküllerinin Belirlenmesi. 2014.

32- Kerekes EB, Deak E, Tako M, Tserennadmid R, Petkovits T, Vagvolgyi C, Krisch J. Anti-biofilm forming and anti-quorum sensing activity of selected essential oils and their main components on food-related micro-organisms. J Appl Microbiol. 2013;115(4):933942.

33-Gür SD., Özyürek SB, Aksöz N, Bilkay IS. Klinik Örneklerden ?zole Edilen Pseudomonas aeruginosa Su?lar?na Bitkisel Ya?lar?n Antimikrobiyal Etkileri. 22. Ulusal Biyoloji Kongresi. 2014:770.34- Alvarez MV, Moreira MR, Ponce A. Antiquorum Sensing And Antimicrobial Activity Of Natural Agents With Potential Use In Food. Journal of Food Safety. 2012;32(3):379-387.

35- Chu W, Zhou S, Jiang Y, Zhu W, Zhuang X, Fu J. Effect of Traditional Chinese Herbal Medicine with Antiquorum Sensing Activity on Pseudomonas aeruginosa. EvidenceBased Complementary and Alternative Medicine. 2013;2013:7. 